\title{
The Differences by Field: Doctoral Students in American Research Universities
}

\author{
Soichiro Aihara*
}

\begin{abstract}
This study analyzes a doctoral student survey conducted as part of the 2010 National Research Council assessment to identify how doctoral students in five major fields are financially supported to publish their papers. The study investigates doctoral students' characteristics, focusing on their primary sources of financial support and their academic activities in five major fields: Biological and Health Sciences, Engineering, Humanities, Physical and Mathematical Sciences, and Social and Behavioral Sciences. The results showed that every field has unique characteristics. The study relies on the framework of doctoral education as an integrated process of research, teaching, and learning. In other words, the outcome of teaching and learning is also the outcome of research, such as the publication of a thesis. In addition, as there are significant differences in scholarly activities in each field of study, the major fields are examined separately. The study is significant because it indicates the foundational conditions that shape excellence in doctoral education. Furthermore, the study survey was conducted as a pilot study. Therefore, although some of the tabulations are included in the report, they have not been analyzed under a consistent framework. This study analyzes the individual data in the archive from an integrated perspective.
\end{abstract}

Keywords: doctoral students, graduate school, National Research Council (NRC), research university.

\section{Introduction}

According to Clark [1], one of the characteristics of higher education in the US is a competitive environment. In this environment, universities in the US have created a center of excellence by integrating research and teaching in their graduate schools. The term "center of excellence" refers to a center of academic excellence because it attracts outstanding people and funding from all over the world. Nevertheless, Gumport [2] suggests that there are fluctuations in the higher education system due to excessive competition. Intensified competition over limited funds acquisition and tightening of the university faculty market disrupt academic activities and reduce the attraction of doctoral education in the US for prospective faculty members and graduate students. TAships (positions as teaching assistants) provide not only valuable experience for

\footnotetext{
* Shibaura Institute of Technology, Tokyo, Japan
} 
graduate students but also contribute to their financial support and allow faculty members to secure research time. Excessive dependence on TAs, however, can delay doctoral students' graduation. Gumport [2] addresses the balance between consensus and conflict in the higher education system. From the perspective of integrating research-education-learning, it is important that financial support for doctoral students is not the same in effect as that provided for TAships.

The aim of this study is to identify how doctoral students in each major field are financially supported to publish their papers. To do so, this study relies on the framework of doctoral education as an integrated process of research, teaching, and learning. In other words, in a doctoral program, the outcome of teaching and learning is also the outcome of research, such as the publication of a thesis. Furthermore, considering which perspective is more suitable for understanding or informing us about doctoral education, we need to focus on the diversity of the doctoral programs, especially by major fields. This paper examines the doctoral programs in terms of differences between major fields based on surveys conducted with doctoral candidates in the US.

The National Research Council (NRC) has assessed doctoral programs at research universities several times. The 2006 survey for 2010 assessment can be said to be the prototype of the Graduate Student Experience in the Research University (gradSERU) initiated by the University of California, Berkeley, and others. Using the framework of gradSERU, this paper focuses on differences by major field, and examines the characteristics of doctoral students, their financial support, and their academic activities such as publishing peer-reviewed papers. According to Clark [1], the higher education system in the US forms a global academic center, because universities have integrated a research-education-learning environment into graduate schools with competitive environments and abundant research funding. This paper examines doctoral programs in the US based on the data of doctoral students from the viewpoint of researcheducation-learning integration. Although these findings cannot be directly applied to Japan due to the different historical backgrounds and contexts of Japan and the US, this study will provide insights for developing initiatives for graduate education reform in Japan.

\section{Data and Framework}

\subsection{Doctoral Student Survey 2006}

The data analyzed in this study were derived from the National Research Council (NRC) [3]. The NRC has been conducting ranking assessments of doctoral programs at research universities in the US about once every ten years since 1982. These assessments have been published three times in 1982, 1995, and 2010, with significant changes in the 2010 assessment [4]. The 2010 assessment included ranking surveys of 5,004 doctoral programs at 212 universities. This survey covers almost all research universities in the U.S, and the objective is to ensure excellence in America's research universities. One survey of doctoral candidates was a preliminary pilot survey conducted in 2006. The NRC intends to use doctoral student surveys for assessment indicators in the futures. However, the survey results of 2006 didn't use for the NRC's assessment indicators in 2010. This paper analyzes the doctoral candidate student survey conducted in 2006. The research question concerns identifying how doctoral students in each major field are financially supported to publish their papers. The study is significant because it indicates the fundamental conditions that shape excellence in doctoral education. 
The 2010 assessment included significant changes as the NRC had divided the 2006 doctoral candidates into five major fields: Biological and Health Sciences, Engineering, Humanities, Physical and Mathematical Sciences, and Social and Behavioral Sciences. During the survey (hereinafter referred to as "Doctoral Student Survey 2006") 16,439 questionnaires were distributed, and 11,589 responses were collected (recovery rate 70\%). The questionnaire enquired into various aspects of doctoral students' experiences, including characteristics, satisfaction, financial support, academic activities, and career goals. Some of the findings were published in the report. However, this student survey was conducted as a pilot study, and the results were not used for the 2010 assessment of the doctoral program. Therefore, the report only included some of the student survey results, which were stored in the archive of the Inter-University Consortium for Political and Social Research (ICPSR). This paper analyzes the raw data of the doctoral student survey stored in this archive. The distribution of doctoral students in the five major fields is shown in Table 1.

Table 1: Five major fields examined in this study

\begin{tabular}{c|r|r|r|r}
\hline & (n) & Percent & Valid Percent & $\begin{array}{c}\text { Cumulative } \\
\text { Percent }\end{array}$ \\
\hline $\begin{array}{c}\text { Biological and } \\
\text { Health } \\
\text { Sciences }\end{array}$ & $(1,579)$ & 13.0 & 13.3 & 13.3 \\
\hline $\begin{array}{c}\text { Engineering } \\
\text { Humanities }\end{array}$ & $(1,850)$ & 15.2 & 15.6 & 28.9 \\
\hline $\begin{array}{c}\text { Physical and } \\
\text { Mathematical } \\
\text { Sciences }\end{array}$ & $(3,620)$ & 22.0 & 22.5 & 51.3 \\
\hline $\begin{array}{c}\text { Social and } \\
\text { Behavioral } \\
\text { Sciences }\end{array}$ & $(2,166)$ & 29.8 & 30.5 & 81.8 \\
\hline Total & $(11,885)$ & 17.8 & 18.2 & 100.0 \\
\hline Missing Value & $(253)$ & 97.9 & 100.0 & \\
\hline Total & $(12,138)$ & 100.0 & & \\
\hline
\end{tabular}

Source: Author, created from BROADFID of the Doctoral Student Survey 2006 by NRC.

\subsection{Framework and Viewpoints for Assessment}

\subsubsection{Framework for Assessment}

This study analyzes doctoral education from an integrated perspective of research-teachinglearning. The gradSERU framework by the University of California, Berkeley is used as a concrete model. This model was developed by Tinto and is based on his theory of graduate communities and doctoral persistence [6]. His model is explained as a type of I-E-O model comprising pre-enrollment information (I), environment (E), and outcomes (O) [7][8]. The education process at graduate school corresponding to environment (E), however, has three 
stages: (1) entry/transition, (2) development, and (3) degree completion/exit. The entry/transition stage occurs primarily during the first year, during which doctoral students build relationships with academic and social communities through formal and informal interactions with faculty and classmates inside and outside the university. The development stage is the period in which doctoral students acquire knowledge and cultivate the competencies necessary for writing dissertations and conducting research. At this stage, doctoral students integrate the academic and social systems of their departments and programs and seek opportunities to develop their expertise. The final degree completion/exit stage occurs when a doctoral student acquires doctoral candidate status and conducts doctoral research. Doctoral candidates successfully complete their research project and assert the legitimacy of their dissertation. During this stage, relationships with dissertation advisors and dissertation committee members are important. In addition, as in the first two stages, external commitments (i.e., responsibilities to work and family) and financial support play a very important role in the experience of doctoral students. Figure 1 shows only the degree completion /exit stage, taken from the framework of Tinto [6]. Using the model of gradSERU developed by Tinto, we can analyze doctoral education under the framework of an integrated process of research-education-learning.

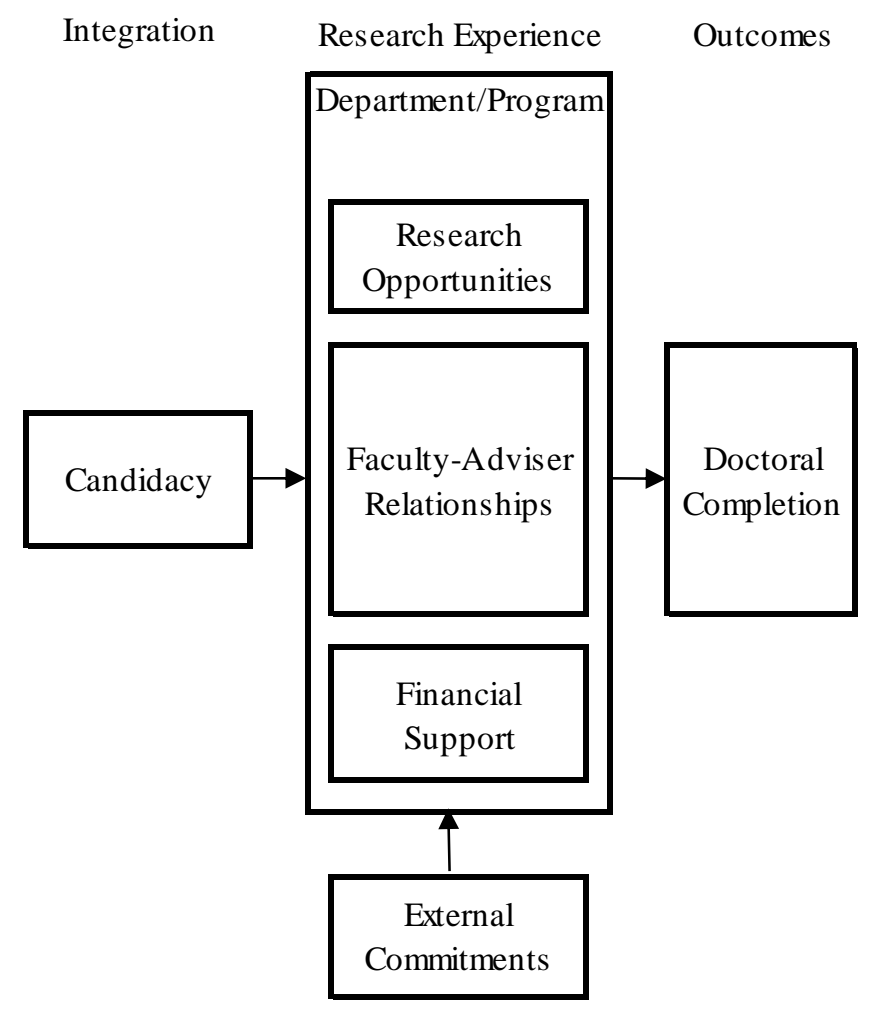

Source: Tinto (1993), p.240.

Figure 1: A longitudinal model of doctoral persistence at the 3rd stage

\subsubsection{Viewpoints for Assessment}

The viewpoint for assessment is based on (1) differences between the major fields, (2) the I-E-O model from Astin's work, and (3) the integration of research-teaching-learning from the results of comparative higher education research. First, the experience of doctoral students is expected to vary greatly in their major fields. Second, following Astin's I-E-O model [7][8], this study 
assesses the experience of doctoral students at three points: pre-enrollment information (I), environment (E), and outcomes (O). In this study, pre-enrollment information (I) deals with the characteristics of the doctoral students; environment (E) deals with financial support; and outcomes $(\mathrm{O})$ deals with academic activities of the doctoral students. Third, the concept of integration of research-education-learning is derived from the study of comparative higher education [1]. Clark considers this concept to be a "perfect fusion of research, education, and student learning." It is the relationship between how teachers and students engage in closely coupled research that can become a mode of education and effective learning [1]. The integration of research-education-learning is also a magnet that attracts resources, power, and prestige, as countries respect it, scholars pursue it, and universities subsidize it [1]. The strength of research universities in the US formed this integration of elements [1], and is the reason this study applies the concept as an assessment perspective.

\section{Characteristics of Doctoral Students}

\subsection{Age}

The mode among the age range of doctoral students is 25-29 years (54.2\%). However, in the Humanities, the mode of the range is 30-34 years (35.4\%). Doctoral candidates in the Humanities tend to be older than other students, and more than $30 \%$ of Humanities students are over 35 .

\subsection{Gender}

Overall, nearly two-thirds of students are men (61.3\%). In Physical and Mathematical Sciences, $79.9 \%$ of students are men. On the other hand, in Biological and Health Sciences and Humanities, women made up more than half, at $52.8 \%$ and $64.5 \%$, respectively.

\subsection{Race/Ethnicity}

Most doctoral students are white (65.9\%), and the second largest group is Asian (31.0\%). Other races/ethnicities examined include Hispanic or Latino, Native American, and Black/African American. In the Humanities, white students constitute the largest group (86.9\%), whereas in Engineering the majority of students are Asian (47.9\%).

\subsection{Career Goal}

The primary career goal of most doctoral students when they entered the program was research and development $(69.6 \%)$ or teaching $(23.2 \%)$. As doctoral candidates, their primary goal changed slightly: research and development (64.8\%) and teaching (21.1\%). Over half of the students majoring in the Humanities saw teaching as the primary goal. When they entered the program versus when they became doctoral candidates, teaching was the primary goal for $57.2 \%$ and $51.7 \%$ of students, respectively. The most significant decreases in the primary career goal between program entry and doctoral candidacy were observed in the Biological and Health Sciences (-14.7\% points) and Physical and Mathematical Sciences (-6.3\% points). 
Table 2: Characteristics of doctoral students

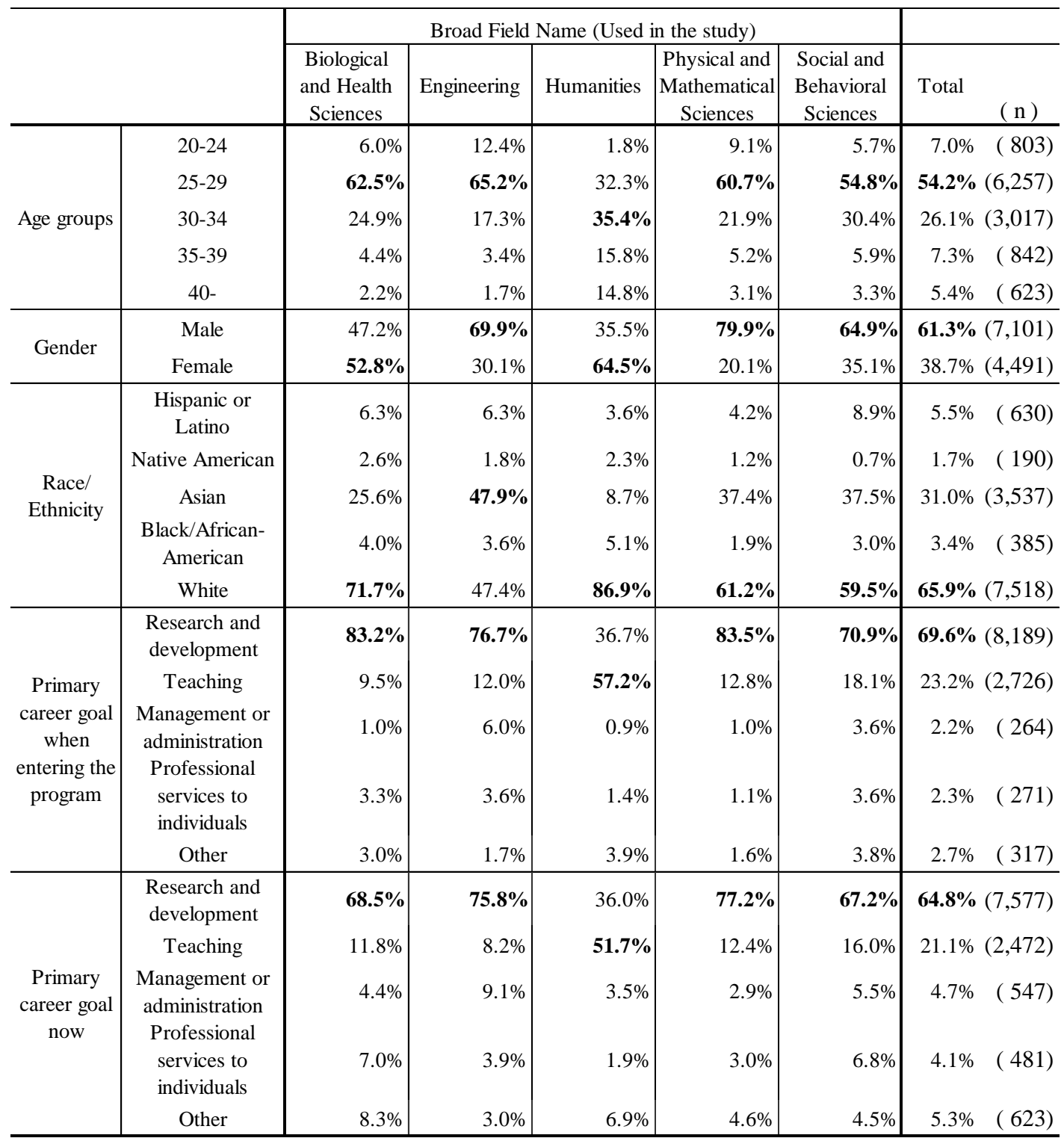

Source: Author, created from E1, E6, E8, E10-1 E10_5, B1_1, B2_1 of the Doctoral Student Survey 2006 by NRC.

\section{Financial Support for Doctoral Students}

Financial support occupies a significant position in the framework [6]. To complete a doctoral dissertation, candidates need sufficient financial resources for research, as they spend considerable time completing research projects [6]. There is a significant difference between support in the form of fellowships and support in the form of teaching assistance [6]. Financial support is indispensable for doctoral students continuing their studies, and the form of support has a considerable effect [6]. 


\subsection{Prior research in Japan}

In Japan, the role of financial support for doctoral students in graduate schools in the US has been known since the 1970s when systematic research on higher education began. In the 1980s, empirical research was conducted on the effects of financial support on academic productivity, and in the 1990s financial support for doctoral students was systematically described as a characteristic of the US graduate education system.

According to Kitamura [10], financial support from the US federal government and the state played a decisive role in expanding graduate school education. In the 1960s, financial support from the federal government was intensively invested in doctoral programs at graduate schools. Federal funds were invested in graduate school and research activities, such as (1) sponsoring research and contracting research expenses, (2) student scholarships, (3) facility and equipment subsidies, and (4) direct grants to universities. Most of these funds were earmarked for doctoral programs and their students. Federal funds were invested heavily in specific disciplines, such as Physical Sciences and Medicine, with little support for Economics. Leading universities with prestigious programs were provided generous support.

Okugawa [11] calculated an objective assessment indicator, which is the scholarship rate based on the percentage of graduate students who received national-level research scholarships between 1975 and 1979, and revealed that universities with a high "scholarship rate" also have high academic productivity. Furthermore, Yamamoto [12] states that "U.S. doctoral students, especially in the science and engineering programs, generally pay tuition and living expenses through federal government fellowships or research funds, or various programs with universities such as educational assistance. It is also essential for universities to develop an aid program to secure excellent graduate students."

According to Yamamoto [12], there are four main aid programs. The first is federal fellowships, which are usually paid directly to students. Students use these funds to choose a graduate school where they can conduct their chosen research. Graduate schools accepting fellowship students will receive tuition fees from the fellowship and students receive a predetermined stipend. Second, traineeships are a collective expenditure (block grant) of the federal government, which presents specific manpower requests to the universities. The federal government selects a target university in response to an application from the university, which in turn uses the funding to select students. As with fellowships, funding covers student fees and tuition. Third, research assistantships allow universities to employ graduate students as research assistants (RAs) who support faculty members. Research grants awarded to university faculty from federal government programs are used for graduate student salaries and tuition. Fourth, teaching assistantships allow universities to employ graduate students as teaching assistants (TAs), in return for services such as class assistance, experiment and practical training, and conducting examinations. These teaching assistantships provide a certain amount of pay in addition to tuition exemption.

\subsection{Prior research in the US}

There are many scholarship-related studies on doctoral students in the US. In this context, Berelson [13] comprehensively examined the past, present, and future of American graduate schools during the time of rapid expansion that is the 1960's. As cited in Kitamura [10], Berelson [13] demonstrated "that fellowships are the most advantageous for doctoral students, teaching assistantships are the least advantageous and research assistantships are somewhere between the two." Bowen and Rudenstine [14] examined Berelson's opinion on financial support in the field 
of Liberal Arts. For instance, he found that doctoral students who received teaching assistantships (TAs) in the first half of their doctoral program had higher completion rates. The authors explained this outcome as a result of a socialization effect. In other words, the effects of financial support differ with the stage of graduate school education. Nettles and Millett [15] also developed a framework to assess doctoral student experience and conducted comprehensive empirical studies based on a large-scale survey $(n=9,036)$. However, it cannot be said that the framework has well organized indicators for pre-entrance information (I), environment (E), and outcomes (O). A large outcome domain is located at the center of the framework surrounded by other domains and indicators. Outcome indicators include financial support, socialization, research productivity, satisfaction, absence from school, and acquiring the degree.

\subsection{Results of the doctoral student survey}

Table 3 displays the results regarding financial support for doctoral students.

\subsubsection{Travel Funds}

More than two-thirds of doctoral students have received travel funds for research presentations at regional/national/international meetings (65.2\%). Biological Sciences (74.9\%) and Engineering (71.1\%) have received more support than other major fields, whereas less than half of the doctoral students in Social and Behavioral Sciences have received travel funds (40.8\%).

\subsubsection{Full Support}

Full support means that doctoral students receive the money they need to cover their tuition and living expenses. More than $80 \%$ of doctoral students receive full support $(83.3 \%)$. The least is received by the Humanities, with nearly $70 \%$ receiving full support (69.9\%). Partial support is received by $16.7 \%$ of students overall and $30.1 \%$ of students in the Humanities.

\subsubsection{Top three sources of financial support}

The primary sources for Biological and Health Sciences were 1) institutional fellowship/stipend (60.2\%), 2) national fellowship/scholarship (32.2\%), and 3) traineeship (19.0\%). Primary sources for Engineering were 1) research assistantship (74.4\%), 2) teaching assistantship (39.2\%), and 3) institutional fellowship/stipend (33.8\%). The primary sources for Humanities were 1) teaching assistantship (82.0\%), 2) institutional fellowship/stipend (51.2\%), and 3) loans (30.2\%). Financial sources in the Humanities also included personal earnings during graduate school $(17.9 \%)$ and spouse/partner/family earnings and savings (22.1\%). The primary sources for Physical and Mathematical Sciences were 1) research assistantship (78.7\%), 2) teaching assistantship (61.3\%), and 3) institutional fellowship/stipend (22.0\%). The ratio of teaching assistantship is high (61.3\%) among Natural Sciences, whereas the ratio of institutional fellowship/stipend is low (22.0\%). The primary sources in Social and Behavioral Sciences were 1) teaching assistantship $(76.8 \%), 2)$ institutional fellowship/stipend $(40.2 \%)$, and 3 ) research assistantship (38.2\%).

Many doctoral students in the Liberal Arts receive teaching assistantships compared to those in the Natural Sciences. Furthermore, as indicated in Table 3, there are many students who depend on personal income, loans, personal savings, and income and savings from spouses and families. 
If we evaluate financial support in terms of integrating research-teaching-learning, teaching assistantship will make this integration more difficult because students will spend more time on educational labor. Personal income, loans, personal savings, etc. will also make integration more difficult because students will spend more time to pay for their tuition fees, not on research and learning.

Table 3: Financial support for doctoral students

\begin{tabular}{|c|c|c|c|c|c|c|c|}
\hline & & \multicolumn{5}{|c|}{ Broad Field Name (Used in the study) } & \multirow[b]{2}{*}{$\begin{array}{l}\text { Total } \\
\end{array}$} \\
\hline & & $\begin{array}{l}\text { Biological } \\
\text { and Health } \\
\text { Sciences } \\
\end{array}$ & Engineering & Humanities & \begin{tabular}{|c|} 
Physical and \\
Mathematical \\
Sciences \\
\end{tabular} & $\begin{array}{c}\text { Social and } \\
\text { Behavioral } \\
\text { Sciences } \\
\end{array}$ & \\
\hline $\begin{array}{l}\text { Receive travel funds for research } \\
\text { presentations at } \\
\text { regional/national/international meetings }\end{array}$ & Yes & $74.9 \%$ & $71.1 \%$ & $68.7 \%$ & $69.8 \%$ & $40.8 \%$ & $65.2 \%(7,674)$ \\
\hline $\begin{array}{c}\text { Degree support of } \\
\text { fellowship/scholarship/traineeship/assist } \\
\text { antship provided }\end{array}$ & $\begin{array}{c}\text { Full } \\
\text { support } \\
\text { Partial } \\
\text { support } \\
\end{array}$ & $\begin{array}{l}\mathbf{8 8 . 5 \%} \\
11.5 \%\end{array}$ & $\begin{array}{l}\mathbf{8 9 . 2 \%} \\
10.8 \%\end{array}$ & $\begin{array}{l}69.9 \% \\
\mathbf{3 0 . 1 \%}\end{array}$ & $\begin{array}{l}\mathbf{8 8 . 9 \%} \\
11.1 \%\end{array}$ & $\begin{array}{l}\mathbf{8 1 . 6 \%} \\
18.4 \%\end{array}$ & $\begin{array}{l}\mathbf{8 3 . 3 \%}(9,223) \\
16.7 \%(1,845)\end{array}$ \\
\hline \multicolumn{8}{|c|}{ Your largest sources of financial support, up to three sources } \\
\hline National fellowship/scholarship & Yes & $32.2 \%$ & $17.9 \%$ & $7.0 \%$ & $10.0 \%$ & $7.7 \%$ & $13.1 \%(1,544)$ \\
\hline Institutional fellowship/stipend & Yes & $60.2 \%$ & $33.8 \%$ & $51.2 \%$ & $22.0 \%$ & $40.2 \%$ & $\mathbf{3 8 . 8 \%}(4,567)$ \\
\hline $\begin{array}{c}\text { Traineeship largest source of financial } \\
\text { support during doctoral program }\end{array}$ & Yes & $19.0 \%$ & $2.4 \%$ & $0.0 \%$ & $0.9 \%$ & $1.1 \%$ & $3.4 \% \quad(399)$ \\
\hline Teaching assistantship & Yes & $17.1 \%$ & $39.2 \%$ & $82.0 \%$ & $61.3 \%$ & $76.8 \%$ & $\mathbf{5 9 . 4 \%}(6,994)$ \\
\hline Research assistantship & Yes & $32.5 \%$ & $74.4 \%$ & $12.1 \%$ & $78.7 \%$ & $38.2 \%$ & $49.6 \%(5,837)$ \\
\hline Personal earning during graduate school & Yes & $2.1 \%$ & $1.0 \%$ & $17.9 \%$ & $1.9 \%$ & $6.0 \%$ & $6.1 \% \quad(722)$ \\
\hline Loans & Yes & $7.4 \%$ & $3.4 \%$ & $30.2 \%$ & $4.1 \%$ & $8.3 \%$ & $11.0 \%(1,300)$ \\
\hline Personal savings & Yes & $3.4 \%$ & $3.5 \%$ & $9.1 \%$ & $2.6 \%$ & $7.7 \%$ & $5.2 \% \quad(618)$ \\
\hline Spouse/partner/family earnings/savings & Yes & $8.3 \%$ & $4.1 \%$ & $22.1 \%$ & $4.3 \%$ & $10.1 \%$ & $9.9 \%(1,160)$ \\
\hline
\end{tabular}

Source: Author, created from BRODAFID, A9, A12_1 A12_5, A12_8 A12_11, A13 of the Doctoral Student Survey 2006 by NRC.

In terms of financial support for doctoral students by major field from the perspective of integrating research-education-learning, Biological and Health Sciences receive the most fellowships, scholarships, and incentives from the government and institutions. Second, Physical and Mathematical Sciences and Engineering have more research assistants than other fields. However, Engineering receives more fellowships, and scholarships from the government and institutions. If we evaluate financial support in terms of integrating research-teaching-learning, research assistantships may make this integration more difficult if students spend too much time in assistive work, whereas fellowships and scholarships would facilitate integration by helping students devote themselves to research and learning. Therefore, the integration of researcheducation-learning in Physical and Mathematical Sciences is strong. Social and Behavioral Sciences and the Humanities receive many teaching assistantships. However, in the Humanities, although some support is received from fellowships and incentives from universities, many students rely on their own income and savings, and on loans. Therefore, Humanities can be assessed as having a weaker integration of research-education-learning than Social and Behavioral Sciences. 


\section{Academic Activity of Doctoral Students}

Academic and research engagement accounts for a large proportion of research behavioral studies at research universities and graduate schools. For doctoral students, the publication of a peerreviewed paper is not only proof that they have acquired knowledge and skills through graduate education and research but also proof that they have acquired the ability to conduct research. Publishing articles also helps students acquire external funding for future academic activities. Tinto's framework [6] shows progress in academic and social integration by graduate students, as well as the strong integration of research-education-learning. However, the tight market for research and development jobs, such as tenure track faculty positions, may encourage heavy competition in graduate students' academic activities and cause them to neglect their coursework. The National Academies of Sciences, Engineering, and Medicine [16] scrutinized the requirements for completion of graduate curricula and courses and recommended that STEM education in the 21st century eliminate the rules to extend the term of completion, such as a firstauthor publication requirement.

\subsection{Prior research in Japan}

The National Institute of Science and Technology Policy [17] aims to understand the conditions of research environments (especially research time and support) at Japanese universities and to find ways to improve them. The Institute conducted a survey using two types of questionnaires, one for faculty and one for students. Fifty students in the second half of their doctoral programs responded to the student questionnaire. The questions related to the number of papers (in Japanese and foreign languages), books, patent applications, invited lectures, and presentations at conferences that were produced by the students and faculty. Based on the findings, it was deemed urgently necessary to ensure that "university faculty can secure the quality and quantity of research time" and that "doctoral and master's students can concentrate on research and education" [17]. In other words, integration of research-education-learning was shown to be an urgent issue.

In addition, Igami, Sayaka, and Tomizawa [18] stated that "when considering measures at the national level and research management at individual universities, it is important to understand the process of linking inputs and outputs for designing incentives and allocating resources." They conducted a survey to investigate the status of research activities that generate academic papers (academic paper status survey) for authors of papers published between 2004 and 2012. They discovered that "Junior researchers (undergraduate and graduate students (master), graduate students (doctors, post doctors)) participate in many research activities at universities. They play an important role" [18]. However, this research does not investigate graduate school education or the experience of doctoral students.

\subsection{Prior Research Overseas}

Some prior studies have been conducted overseas. Larivière [19] surveyed the Web of Science (WoS) for authors of peer-reviewed papers published between 2000 and 2007 among doctoral students in Quebec. The results showed that in the Medical and Natural Sciences, about 30\% of the papers were authored or coauthored by doctoral students. This number was $19 \%$ for Social Sciences and 13\% for Humanities. The authors propose that peer-reviewed papers are more important than doctoral dissertations in Medical and Natural Sciences because of differences in 
the major fields. Furthermore, they point out the relationship between doctoral students and their advisor faculty. In the Medical and Natural Sciences, doctoral students attend lab every day. They are involved not only in their own research, but also in projects that other students, postdocs, and professors are working on in the lab. Doctoral students' research is often part of a larger research project, and it is difficult to distinguish the research conducted only by the students. Collaborative research is an important factor in the socialization of doctoral students, with more students involved in producing peer-reviewed papers. On the other hand, in the Social Sciences and Humanities, doctoral students tend to study at home or in the library rather than work with advisor faculty. Advisor faculty also tend to conduct their research individually, rather than in teams.

In the US, Pinheiro, Melkers, and Youtie [20] reviewed published papers by doctoral students as a measure of their pre-doctoral research activities and future academic success. The number of papers authored over a lifetime by researchers at Type I research universities of the Carnegie Classification was examined using Web of Science (WoS) and combined with the data from questionnaires. The results show that doctoral student publications have increased; many students did not publish at all 20 to 30 years ago, whereas today students publish at least one study. Additionally, students who published their study while in a doctoral program had a higher number of publications over their lifetime. Co-authorship with advisor faculty is an important driver of academic activity, along with the characteristics of students (gender and race) and majors.

In addition, Horta and Santos [21] analyzed the effects of paper publication by doctoral students on future knowledge production, citations, and co-authorship. Researchers were selected to represent all disciplines in Portugal and the number of lifetime papers was examined using Web of Science (WoS). The results showed that researchers who published papers as doctoral students published more papers in their lifetime than those who did not. Productivity regarding the number of papers, annual and lifetime citations, single authorship, and international coauthorship was high.

Horta and Santos [21] explain the publication of papers by doctoral students with human capital theory, signaling theory, and developmental theory.

Human capital explains that post-degree work requires the ability to acquire postgraduate doctoral studies and will determine most of the future productivity. Signal theory, on the other hand, states that employers cannot understand the potential productivity of doctoral students in an uncertain environment. The publication of papers by doctoral students serves as a signal in the talent pool of potential general abilities, learning attitudes, and motivating characteristics. The development theory states that individuals need to fulfill their role tasks to the fullest according to their career stages. On the other hand, the organization designs support and remuneration systems to improve the vitality of the members and the effectiveness of the organization. In development theory, the publication of papers by doctoral students is a developmental issue in doctoral programs.

These three theories are similar in that academic activities of doctoral students are accounted for by social factors. That is, publication by doctoral students is explained in response to social demands rather than integration of research-education-learning.

\subsection{Results of the doctoral student survey}

Table 4 shows the distribution of the number of peer-reviewed papers published by doctoral students. The status of publication by the author or co-author during their doctoral program enrollment period is shown for men and women by their major fields. The target of doctoral 
student surveys is doctoral candidates, and thus, the enrollment period is three to five years or more. Among doctoral students who did not write any peer-reviewed papers while enrolled, 43.3\% are men and 54.7\% are women. Among students who wrote one paper, $18.0 \%$ are men and $19.4 \%$ are women. Half of the doctoral candidates have not published peer-reviewed papers. However, there are significant differences in major fields. In Biological and Health Sciences, Engineering, and Physical and Mathematical Sciences, 60 to $70 \%$ of doctoral students published one or more peer-reviewed papers. On the other hand, nearly 60 to $80 \%$ of doctoral students in Social and Behavioral Sciences and the Humanities have not published peer-reviewed papers.

To assess doctoral programs from the viewpoint of integrating research-education-learning, attention must be paid to differences in research styles and presentation styles specific to the major fields. It is also necessary to consider the characteristics of doctoral students, and the learning environment of graduate school, such as financial support.

Table 4: Number of peer-reviewed papers by doctoral students

\begin{tabular}{|c|c|c|c|c|c|c|c|c|c|c|}
\hline & & 0 & 1 & 2 & 3 & 4 & 5 & 6 & $\begin{array}{c}7 \text { or } \\
\text { more }\end{array}$ & $(\mathrm{n})$ \\
\hline \multirow{2}{*}{$\begin{array}{l}\text { Biological and Health } \\
\text { Sciences }\end{array}$} & Men & $27.2 \%$ & $24.1 \%$ & $18.9 \%$ & $13.8 \%$ & $6.4 \%$ & $3.8 \%$ & $2.5 \%$ & $3.3 \%$ & $100.0 \% \quad(734)$ \\
\hline & Women & $35.2 \%$ & $26.1 \%$ & $17.3 \%$ & $11.5 \%$ & $5.0 \%$ & $2.6 \%$ & $1.2 \%$ & $1.1 \%$ & $100.0 \% \quad(820)$ \\
\hline \multirow{2}{*}{ Engineering } & Men & $29.7 \%$ & $18.2 \%$ & $16.8 \%$ & $10.8 \%$ & $9.1 \%$ & $5.6 \%$ & $2.7 \%$ & $7.2 \%$ & $100.0 \% \quad(1,269)$ \\
\hline & Women & $32.4 \%$ & $21.6 \%$ & $15.0 \%$ & $10.4 \%$ & $9.2 \%$ & $4.6 \%$ & $3.3 \%$ & $3.5 \%$ & $100.0 \% \quad(546)$ \\
\hline \multirow{2}{*}{ Humanities } & Men & $63.4 \%$ & $21.3 \%$ & $8.8 \%$ & $3.4 \%$ & $1.5 \%$ & $0.6 \%$ & $0.1 \%$ & $1.0 \%$ & $100.0 \% \quad(925)$ \\
\hline & Women & $68.9 \%$ & $19.2 \%$ & $7.2 \%$ & $2.5 \%$ & $1.0 \%$ & $0.4 \%$ & $0.3 \%$ & $0.5 \%$ & $100.0 \% \quad(1,677)$ \\
\hline \multirow{2}{*}{$\begin{array}{l}\text { Physical and } \\
\text { Mathematical Sciences }\end{array}$} & Men & $30.5 \%$ & $17.9 \%$ & $13.9 \%$ & $10.7 \%$ & $7.6 \%$ & $5.4 \%$ & $4.1 \%$ & $9.9 \%$ & $100.0 \% \quad(2,807)$ \\
\hline & Women & $34.5 \%$ & $18.9 \%$ & $15.3 \%$ & $9.9 \%$ & $5.8 \%$ & $5.9 \%$ & $1.8 \%$ & $7.9 \%$ & $100.0 \% \quad(708)$ \\
\hline \multirow{2}{*}{$\begin{array}{l}\text { Social and Behavioral } \\
\text { Sciences }\end{array}$} & Men & $77.2 \%$ & $12.4 \%$ & $5.6 \%$ & $3.0 \%$ & $1.1 \%$ & $0.1 \%$ & $0.3 \%$ & $0.3 \%$ & $100.0 \% \quad(1,366)$ \\
\hline & Women & $79.9 \%$ & $11.2 \%$ & $4.9 \%$ & $2.2 \%$ & $1.4 \%$ & $0.3 \%$ & $0.0 \%$ & $0.3 \%$ & $100.0 \% \quad(740)$ \\
\hline \multirow{2}{*}{ Total } & Men & $43.3 \%$ & $18.0 \%$ & $12.7 \%$ & $8.6 \%$ & $5.7 \%$ & $3.6 \%$ & $2.4 \%$ & $5.7 \%$ & $100.0 \% \quad(7,101)$ \\
\hline & Women & $54.7 \%$ & $19.4 \%$ & $10.9 \%$ & $6.2 \%$ & $3.5 \%$ & $2.2 \%$ & $1.0 \%$ & $2.1 \%$ & $100.0 \% \quad(4,491)$ \\
\hline
\end{tabular}

Source: Author, created from BROADFID,E1,A11_A_2, and A11_NONE_2 of the Doctoral Student Survey 2006 by NRC.

Note: During doctoral program, include author or co-author, and accepted for publication but not yet published.

\section{Summary}

Graduate schools in the US form a world-class academic center. This study investigated a doctoral student survey conducted as part of the National Research Council 2010 assessment. Characteristics of doctoral students in five major fields were examined, including primary sources of financial support and academic activities. The study results showed unique characteristics of each major field.

In the Biological and Health Sciences, there are many women, many students who change their career goals, and many students who receive financial support from fellowships. In Engineering, there are many men, many Asian students, and many students who receive support from RAships. In the Humanities, graduate students are older, and there are more women and white students. The amount of financial support provided is relatively low and many students receive TAships. In the Physical and Mathematical Sciences, there are many men, many students who change their career goals, and many students who are supported by both RAships and TAships. In the Social and Behavioral Sciences, there are many men who are mainly supported through TAships.

Half of the doctoral candidates have not published peer-reviewed papers. However, there are significant differences in major fields. In the Biological and Health Sciences, Engineering, and 
Physical and Mathematical Sciences, 60 to $70 \%$ of doctoral students publish one or more peerreviewed papers. On the other hand, nearly 60 to $80 \%$ of doctoral students in the Social and Behavioral Sciences and the Humanities do not publish peer-reviewed papers.

Most of the doctoral students in the US receive full financial support. The exception is students in the Humanities, many of whom support themselves through loans, savings of spouses or partners, and personal earnings. Financial support for doctoral students also includes TAships and RAships. As Gumport [2] points out, excessive reliance on TAships and RAships may be counterproductive, detracting from the integration of the research-teaching-study nexus. In addition, other than doctoral students in the Humanities, most students aim for research and development jobs. However, in the Biological and Health Sciences and Physical and Mathematical Sciences, there are many students who change their career goal. This survey was conducted before the Lehman shock, but tightening of the labor market may be affecting the faculty labor market. Therefore, further research is necessary.

\section{Acknowledgement}

This research is supported by JSPS Research Grant JP18K02735.

\section{References}

[1] B.R. Clark, Places of Inquiry: Research and Advanced Education in Modern Universities, University of California Press, 1995, p.117.

[2] P.J. Gumport, "Graduate Education and Research: Interdependence and Strain," American Higher Education in the Twenty-First Century: Social, Political, and Economic Challenges, 4th ed., M.N. Bastedo, P.G. Altbach, P.J. Gumport, eds., JHU Press, 2016, pp. 110-154.

[3] J.P. Ostriker, C.V. Kuh, and J.A. Voytuk, A Data-Based Assessment of Research-Doctorate Programs in the United States, National Academies Press, 2011.

[4] S. Aihara, "Benchmarking of Doctoral Courses at the American Research Universities: The Role of the National Research Council 2010 Assessment Data," Daigaku Ronshyu; doi:10.15027/45668 [in Japanese].

[5] National Academy of Sciences, National Research Council, "A Data-Based Assessment of Research-Doctorate Programs in the United States, 2005-2006," Inter-university Consortium for Political and Social Research (ICPSR 34318-0003), doi:10.3886/ICPSR34318.v2 [Accessed 14 Oct. 2020].

[6] V. Tinto, Leaving College: Rethinking the Causes and Cures of Student Attrition, 2nd ed., University of Chicago Press, 1993.

[7] A.W. Astin, "Student Involvement: A Developmental Theory for Higher Education," Journal of College Student Personnel, vol. 25, no. 4, 1984, pp. 297-308.

[8] A.W. Astin, Assessment for Excellence: The Philosophy and Practice of Assessment and Evaluation in Higher Education, Oryx Press, 1991. 
[9] B.R. Clark, The Research Foundations of Graduate Education: Germany, Britain, France, United States, Japan, University of California Press, 1993.

[10] K. Kitamura, "The Success and the Crisis in American Graduate Education: From the 'Golden Age' to the 1970's," Daigaku Ronshyu, no. 2, 1974, pp. 16-30. [in Japanese]

[11] Y. Okugawa, "A Statistical Analysis of the Academic Productivity of the Modern American Graduate School,” The Japanese Journal of Educational Research, vol. 54, no. 2, 1987, pp. 166-177. [in Japanese]

[12] S. Yamamoto, "American Graduate School," Contemporary Graduate Education, S. Ichikawa and K. Kitamura, eds., Tamagawa University Press, 1995, pp. 120-137. [in Japanese]

[13] B. Berelson, Graduate Education in the United States, McGraw-Hill, 1960.

[14] W.G. Bowen and N.L. Rudenstine, In Pursuit of the PhD, Princeton University Press, 1992.

[15] M.T. Nettles and C.M. Millett, Three Magic Letters: Getting to Ph.D., Johns Hopkins University Press, 2006.

[16] National Academies of Sciences, Engineering, and Medicine, Graduate STEM Education for the 21st Century, The National Academies Press, 2018, p. 97. doi:10.17226/25038 [Accessed 14 Oct. 2020].

[17] National Institute of Science and Technology Policy, "Analysis of the State of Japanese Universities System - Quantitative and Comparative Study of Research Activity Between Japan and UK and Research Environment Study by Time Budget Survey," NISTEP Report 122, 2009; http://hdl.handle.net/11035/689 [Accessed 14 Oct. 2020]. [in Japanese]

[18] M. Igami, A. Saka, and H. Tomizawa, "Research Funds and Teams of Research Activities that Produced Scientific Publications-Evidence from a Large-Scale Survey to Corresponding Authors of Scientific Publications from 2004 to 2012," NISTEP Discussion Paper 146, 2017; http://hdl.handle.net/11035/3168 [Accessed 14 Oct. 2020]. [in Japanese]

[19] V. Larivière, "On the Shoulders of Students? The Contribution of PhD Students to the Advancement of Knowledge," Scientometrics; doi:10.1007/s11192-011-0495-6.

[20] D. Pinheiro, J. Melkers, and J. Youtie, "Learning to Play the Game: Student Publishing as An Indicator of Future Scholarly Success," Technological Forecasting and Social Change; doi:10.1016/j.techfore.2012.09.008.

[21] H. Horta and J.M. Santos, "The Impact of Publishing During PhD Studies on Career Research Publication, Visibility, and Collaborations," Research in Higher Education; doi:10.1007/s11162-015-9380-0. 